\title{
R Research Soure \\ Estimation of Monthly Mean Global Solar Radiation Over Semi-arid Region, Kadapa Using Meteorological Parameters
}

Pavankumari Sankarayogi ( $\sim$ spavankumariphd@gmail.com )

Yogi Vemana University

Ramanjula Reddy Annareddy

Amit Awasthi

Balakrishnaiah Gugamsetty

Sankar Narayana Pulla

Nazeer Ahammed Yadiki

\section{Research Article}

Keywords: Clearness index, Solar radiation, Sunshine hour, Relative humidity

Posted Date: February 1st, 2022

DOI: https://doi.org/10.21203/rs.3.rs-1227717/v1

License: (c) (1) This work is licensed under a Creative Commons Attribution 4.0 International License.

Read Full License 
1 Estimation of monthly mean global solar radiation over semi-arid region, kadapa using 2 meteorological parameters

3 Pavankumari Sankarayogi ${ }^{*}$, Ramanjula Reddy Annareddy ${ }^{1}$, Amit Awasthi ${ }^{2}$, Balakrishnaiah 4 Gugamsetty $^{3}$, Sankar Narayana Pulla ${ }^{1}$, Nazeer Ahammed Yadiki ${ }^{1}$

$5{ }^{1}$ Atmospheric Science Laboratory, Department of Physics, Yogi Vemana University, Kadapa 516

6 005, Andhra Pradesh, India

$7 \quad 2$ Department of Physics, University of Petroleum and Energy Studies, Dehradun, Uttarakhand 8 248007,India

$9{ }^{3}$ Aerosol \& Atmospheric Research Laboratory, Department of Physics, Sri Krishnadevaraya 10 University, Anantapur 515 003, Andhra Pradesh, India

*Corresponding author:

Dr. Sankarayogi Pavankumari

CSIR Research Associate

Department of Physics

Yogi Vemana University

$$
\text { Kadapa - } 516005
$$

Mobile : 8886764949; 9491944454

\section{Authors' contributions}

Y. Nazeer Ahammed: conceptualized the experiment and edited - Original draft. S. Pavankumari,G Balakrishnaiah, designed the study, data collection and writing the original draft. Amit Awasthi, A. Ramanjula Reddy and P. Sankar 

meteorological parameters

Pavankumari Sankarayogi $1^{*}$, Ramanjula Reddy Annareddy ${ }^{1}$, Amit Awasthi $^{2}$, Balakrishnaiah Gugamsetty ${ }^{3}$, Sankar Narayana Pulla ${ }^{1}$, Nazeer Ahammed Yadiki ${ }^{1}$

${ }^{1}$ Atmospheric Science Laboratory, Department of Physics, Yogi Vemana University, Kadapa 516 005, Andhra Pradesh, India

${ }^{2}$ Department of Physics, University of Petroleum and Energy Studies, Dehradun, Uttarakhand 248007,India

${ }^{3}$ Aerosol \& Atmospheric Research Laboratory, Department of Physics, Sri Krishnadevaraya University, Anantapur 515 003, Andhra Pradesh, India

\section{Abstract}

To accomplish the best operation of available solar energy, it is important to estimate the incident solar radiation over the specific region. The present study focuses on the estimation of solar radiation by using mathematical modelling. For that purpose, monthly average daily global solar radiations are estimated based on different parameters like minimum and maximum temperature, sunshine hour, and relative humidity. The location selected for this study is Kadapa $\left(\left(14.47^{\circ} \mathrm{N}, 78.87^{\circ} \mathrm{E}\right.\right.$, and $138 \mathrm{~m}$ asl) Southern part of India. The study period is from April 2016 to October 2018. The study focuses particularly on models based on the relative sunshine $\left(\mathrm{S} / \mathrm{S}_{0}\right)$ and clearness index $\left(\mathrm{k}_{\mathrm{t}}\right)$. The clearness index and relative sunshine were high in December $(1.058 \pm 0.002$ and $0.968 \pm 0.005)$ and low in July $(0.952 \pm 0.05$ and $0.734 \pm 0.072)$. The estimated clearness index based on sunshine models is best correlated with the calculated clearness index values. In temperature and relative humidity-based models the hybrid parameter-based models are better correlated with the single parameter based-models.

Keywords: Clearness index, Solar radiation, Sunshine hour, Relative humidity.

\section{Introduction}

Solar irradiation at the earth's surface is necessary for the growth and utilization of solar energy. Understanding of solar radiation's availability and variability is of huge significance in Atmospheric Research as well in practical consumption in electricity generation, water heating, etc. In support of designing collectors for the photovoltaic equipment and other solar heater, solar radiation is required in the form of solar energy. Measurements of solar radiation are significant as increasing number of solar heating and cooling applications and the require for exact solar irradiation data to predict performance. The energy transferred to a surface by solar radiation experimentally 
determined by using device which will measure the heating effect of direct solar radiation and diffuse solar radiation (Jatto et al., 2015). Constancy in the weather-system and climate-atmosphere mechanism solar radiation plays a very important role. Direct, Global and diffuse radiation are important radiation parameters used in solar energy techniques (Hussain et al. 1999). information of global solar radiation is of primary importance for all solar energy conversion systems. Incoming global solar radiation is affected by atmospheric environment such as aerosols, air mass, water vapor, ozone and cloud distribution. The attenuation agents are changeable over time and when combined with elevation changes, they significantly influence the spatial pattern of attenuation (Ruiz-Arias et al. 2010). The is indicated by The fraction of extraterrestrial radiation that reaches the earth's surface as global radiation is indicated as the transparency of the atmosphere. It gives the measure of the degree of clearness of the sky (Akhlaque et al. 2009). The quantity of solar radiation reaching the earth's surface is ascertained by the hour of the day, the season of the year, and solar angles, amongst which are the sun's altitude angle, azimuth angle, zenith angle, and declination angle (Ghazi 2014; Fedorov 2019). The solar radiation data calculated at different regions is important in order to determine the potential of solar energy in a specific region. The instruments pyranometer, solarimeter, pyroheliometer etc are measured the components of solar radiation. Because of the expensive measurement devices and the difficult measurement methods it is not practically reasonable to place measurement devices everywhere. So that there was be deficient in of sufficient solar radiation data for establishing solar energy generation systems. The prediction of solar radiation have been more significant for energy and smart grid applications. In order to mounting the appropriate evaluation method of solar radiation is major importance for reducing electricity cost and time loss. For the solar radiation estimation, available Global Solar Radiation (GSR) as output. Model accuracy evaluations like Mean Bias statistically tested based on error calculations. Thus solar radiation models are desired to predict solar radiation by using models and empirical correlations (Prescott 1940). Several empirical models have been proposed to estimate the global solar radiation, using meteorological, climatological parameters such as sunshine hour, minimum and maximum temperature, relative humidity, cloud cover, precipitation and rain fall. These parameters include sunshine hours (Teke 
et al. 2014; Mecibah et al. 2014; Khorasanizadeh 2013; Gana etal. 2013b; Li et al. 2010; Koussa et al. 2009; Bakirci et al. 2009; Bannani et al. 2006; Akinoglu and Ecevit 1990 and Angstrom 1924; air temperature (Muhammad and Darma 2014; Kaltiya et al. 2014; Medugu and Yakubu 2011; Agbo et al. 2010; Fletcher and Moot 2007; Paulescu et al. 2006; Falayi and Rabiu 2005; Allen 1997; Bristow and Campbell 1984; Hargreaves and Samani 1982; relative humidity (Trabea and Shaltout 2000 and Alnaser 1993); precipitation (Rietveld 1978); and cloudiness (Kumar and Umanand 2005).

In the present study, we provide the idea behind different solar radiation estimation models with the methodology used. The most important purpose of this study is to calculate the global solar radiation using Angstrom -Prescott model and compare it with the estimation of global solar radiation using sunshine hour, minimum and maximum temperature and relative humidity $(\mathrm{RH})$ based on clearness index and sunshine ratio in Kadapa region.

\section{Methodology and model approach}

Meteorological parameters such as wind speed, wind direction, temperature, relative humidity and sun shine hour data were collected from MOSDAC (Meteorological and Oceanographic Satellite Data Archive Center). The present analysis was carried out at Yogi Vemana University, Kadapa (YVU; $14.47^{\circ} \mathrm{N}, 78.82^{\circ} \mathrm{E}, 138 \mathrm{~m}$ above sea level), from April 2016 to October 2018. The study area, Kadapa is situated in the central part of Andhra Pradesh is located $8 \mathrm{~km}$ south of the Penna River and is surrounded by the Nallamala $(40 \mathrm{~km})$ and the Palakonda hills $(25 \mathrm{~km})$ on its three sides. Kadapa has a tropical climate and the weather conditions are generally hot. It is an active station under the Aerosol Radiative Forcing over India (ARFI) network of stations. The sampling station is located at adjacent to the highway, at a distance of $15 \mathrm{~km}$ west of the main Kadapa city. Several brick kilns and some small-scale cement and electrical industries around the observational site within a $30 \mathrm{~km}$ radius. In addition, a large number of automobile and vehicular emissions are run through the highway from morning to near-midnight. These emissions are the principal sources of air pollution. Most of the rainfall occurs during monsoon and post- monsoon from the south-west and north-east monsoons respectively.

The temperature was observed to have increased in the summer months, it decreases to its minimum in the monsoon months and the relative humidity $(\mathrm{RH})$ was observed to be high in monsoon months and low in the summer months was shown in Fig. 1 (a) in all the years under study. Figure 1 (b) shows the wind rose diagram for variation of wind speed and wind direction, 
$133 \frac{\mathrm{H}}{\mathrm{H}_{0}}=\mathrm{a}+\mathrm{b}\left(\frac{\mathrm{S}}{\mathrm{S}_{0}}\right)$ and Yakubu 2011).

these are important for monitoring and predicting weather patterns and global climate. Over the study period in the Kadapa region most of the winds blows from the south east direction.

The first model used to estimate the global solar radiation on a horizontal surface based on the sunshine model is described by the equation as (Prescott 1940; Ahmed et al. 2009 and Medugu

$b=18.676\left(\frac{S}{S_{0}}\right)^{2}-29.395\left(\frac{S}{S_{0}}\right)+12.098$

$\mathrm{H}_{0}$ is the monthly mean of daily extraterrestrial solar radiation $\left(\mathrm{W} / \mathrm{m}^{2}\right), \mathrm{H}$ is the monthly mean of daily global solar radiation $\left(\mathrm{W} / \mathrm{m}^{2}\right), \mathrm{S}$ is the monthly mean daily hours of bright sunshine, $\mathrm{S}_{0}$ is the monthly mean day length and $S / S_{0}$ is the relative sunshine, it is found to vary daily and seasonality (Shears et al., 1981) and a, b are regression coefficients. Their values have been obtained from the relationship given by R. C. Srivastava and Harsha Pandey (R.C. Srivastava \& Harsha Pandey, 2013) as

The significance of this relationship lies in the information that using this correlation solar radiation can be estimated for every location in India, even at the places where we do not have a system to measure solar radiation. To compute estimated values of the monthly average daily global solar radiation, the values of $a$ and $b$ were used in Equation (1).

The global solar radiation and sunshine duration vary from day to day, the monthly daily averaged values are used to derive the $a$ and $b$ values. While it is not easy about estimating the daily total amount of global solar radiation on a particular day, using the sunshine duration method allows the rough estimation of monthly value.

151 can be computed from the model of Deffie and Beckman (1991) as follows, 
where $\mathrm{H}_{\mathrm{o}}$ is $\left[\mathrm{MJm}^{-2} \mathrm{day}^{-1}\right]$, solar constant, $\mathrm{G}_{\mathrm{sc}}=0.0820 \mathrm{MJm}^{-2} \mathrm{~min}^{-1}, \mathrm{~d}_{\mathrm{r}}$ is inverse relative 154 distance Earth-Sun, $\omega_{\mathrm{s}}$ is sunset hour angle (rad), $\varphi$ is latitude (rad), $\delta$ is solar declination ( $\left.\mathrm{rad}\right)$.

155

156

157

158

159

160

161

162

extraterrestrial solar radiation $\left(\mathrm{H}_{\mathrm{o}}\right)$ is expressed in the above equation in $\mathrm{MJm}^{-2} \mathrm{day}^{-1}$. The consequent equivalent evaporation in $\mathrm{W} / \mathrm{m}^{2}$ is obtained by multiplying $\mathrm{H}_{\mathrm{o}}$ by 11.6. The symbol $\varphi$ is latitude expressed in radians is positive for the northern hemisphere and negative for the southern hemisphere. The change from decimal degrees to radians is given by:

$[$ Radians $]=\frac{\pi}{180}[$ decimaldegree $]$

The inverse relative distance Earth-Sun, $d_{r}$ and the solar declination, $\delta$ are given by:

$\mathrm{d}_{\mathrm{r}}=1+0.033 \cos \left(\frac{2 \pi}{365} \mathrm{~J}\right)$

$$
\delta=0.409 \sin \left(\frac{2 \pi}{365} \mathrm{~J}-1.39\right)
$$

The sunset hour angle, $\omega_{\mathrm{s}}$ is given by:

$\omega_{\mathrm{s}}=\arccos [-\tan \varphi \tan \delta]$

Monthly average day length $\left(\mathrm{S}_{0}\right)$ is:

$\mathrm{S}_{0}=\frac{2}{15} \omega_{\mathrm{s}}$

The diffuse fraction of models are classified according to the basis of their input parameters such as correlations of clearness index $\left(\mathrm{k}_{\mathrm{t}}\right)$ and relative sunshine $\left(\mathrm{S} / \mathrm{S}_{0}\right)$. It points out the reduction of the incoming global solar radiation by the atmosphere and it gives both the level of availability of solar irradiance at the surface of the earth and the changes in atmospheric conditions (Nwokolo et al. 2017).

The clearness index $\left(\mathrm{k}_{\mathrm{t}}\right)$ is the ratio of the global radiation at ground level on a horizontal surface to the extraterrestrial global solar irradiation. It describes the attenuation of solar radiation due to the clouds and depends on the geographical coordinates of the location.

Based on sky conditions, the $\mathrm{k}_{\mathrm{t}}=\frac{\mathrm{H}}{\mathrm{H}_{0}}$ clearness index $\left(\mathrm{k}_{\mathrm{t}}\right)$ is used to mainly depend on global solar irradiance ( $\mathrm{Li}$ et al., 2004). The value of $\mathrm{k}_{\mathrm{t}}$ is in the range of 012-0.35, 0.35-0.65, $>0.65$ for cloudy, partly cloudy, clear sky conditions, respectively (Kuye and Jagtap 1992). In 2008, the world meteorological organization, classified and proposed the sky condition based on 
sunshine hour, relative sunshine $\left(\mathrm{S} / \mathrm{S}_{0}\right)$ is in the range of $0-0.3,0.3-0.7,0.7-1$ for the cloudy sky, scattered clouds, clear sky, respectively (Yusuf, 2017) (WMO, 2006; Adam, 2012).

\section{Diffuse solar radiation for daily periods}

The total solar radiation consists of direct or beam radiation coming directly from the solar disc and the diffuse component scattered to the ground from the sky dome. The latter depends on the clarity of the sky and could be estimated from the correlation of (Collares-Pereira and Rabl 1979) which gives the daily average diffuse radiation, $\mathrm{H}_{\mathrm{d} \mid}$ as:

$H_{d}=H\left\{0.775+0.0060\left(\omega_{S}-90\right)-\left[0.505+0.00455\left(\omega_{S}-90\right)\right] \cos \left(115 k_{t}-103\right)\right\}$

The diffuse fraction, $K_{d}$ is defined as the ratio of the daily diffuse radiation $\left(H_{d}\right)$ on a horizontal surface to the daily global solar radiation $(\mathrm{H})$ on that surface, that is:

$\mathrm{k}_{\mathrm{d}}=\frac{\mathrm{H}_{\mathrm{d}}}{\mathrm{H}}$

which is the diffusion characteristics of diffuse solar radiation and hence mirrors the effectiveness of the sky in transmitting diffuse solar radiation.

\section{Estimation of global solar radiation using sunshine, temperature and relative humidity:}

To estimating global solar radiation, several models have been proposed. Page, 1964 gives a modified Angstrom type of linear regression model which correlates the global solar radiation with the relative sunshine duration. The correlation between the estimation of global solar radiation using meteorological parameters like a sunshine hour, mean daily maximum and minimum temperature, mean daily relative humidity and bright sunshine data was studied in (Trabea 2000 and Vasudeva Reddy 2018).

\section{Sunshine based models}

The sunshine duration is the most commonly used parameter for the estimation of global solar radiation. This is because sunshine hours can be easily and reliably measured and data are widely available. Most of the models for estimating solar radiation use the sunshine ratio for the prediction of monthly average daily global solar radiation. The earlier studies (Souza et al. 2016; Li et al. 2012; Besharat et al. 2013; Muneer and Munawwar 2006; Ertekin and Yaldiz 1999) reported that the Angstrom-Prescott sunshine-based model yielded the best correlation on single 
variable basis with the clearness index. Therefore, it is the most accepted worldwide model for estimating global solar radiation based on a single variable. The models are (Prescott 1940; Ogelman et al. 1984; El-Metwally 2005; Bakirci 2009).

(1) Angstrom- Prescott model This model (Prescott 1940) is the most commonly used model and it is given by

$$
\frac{\mathrm{H}}{\mathrm{H}_{0}}=\mathrm{a}+\mathrm{b}\left(\frac{\mathrm{S}}{\mathrm{S}_{0}}\right)
$$

Where $\mathrm{H}$ is the monthly mean global solar radiation $\left(\mathrm{W} / \mathrm{m}^{2}\right), \mathrm{H}_{0}$ is the extraterrestrial solar radiation $\left(\mathrm{W} / \mathrm{m}^{2}\right), \mathrm{S}$ is the actual sunshine duration (hours), $\mathrm{S}_{0}$ is the maximum day length (hours) and the values $\mathrm{a}$ and $\mathrm{b}$ are regression coefficients obtained from the graph of $\mathrm{H} / \mathrm{H}_{0}$ against $\mathrm{S} / \mathrm{S}_{0}$.

(2) Ogelman et al model

Ogelman developed the following model for estimating global solar radiation (Ogelman 1984).

$$
\frac{\mathrm{H}}{\mathrm{H}_{0}}=\mathrm{a}+\mathrm{b}\left(\frac{\mathrm{S}}{\mathrm{S}_{0}}\right)+\mathrm{c}\left(\frac{\mathrm{S}}{\mathrm{S}_{0}}\right)^{2}
$$

Where $\mathrm{a}, \mathrm{b}$ and $\mathrm{c}$ are regression coefficients.

(3) El-Metwally model

The following model was developed by El-Metwally for estimating global solar radiation (El-Metwally 2005).

Where a is regression coefficient.

(4) Bakirci exponential model Bakirci developed the following model for estimating global solar radiation (Bakirci 2009).

$$
\frac{\mathrm{H}}{\mathrm{H}_{0}}=\mathrm{a}\left(\frac{\mathrm{S}}{\mathrm{S}_{0}}\right)^{\mathrm{b}}
$$

Where $a$ and $b$ are regression coefficients. 


\section{Temperature based models}

236 The Hargreaves and Samani (1982) and the Garcia (1994) models are both temperature-based 237 models as they employ maximum and minimum temperatures (temperature range) as the 238 required meteorological data.

239 (1) Hargreaves and Samani model

240 This model gives the relation between clearness index and thermal amplitude $\Delta \mathrm{T}$ based on 241 the specification of an empirical coefficient of proportionality $\left(\mathrm{k}_{\mathrm{r}}\right)$ and depends on the location and altitude of the station (Allen et al. 1998). This is given by the relation

$$
\frac{\mathrm{H}}{\mathrm{H}_{0}}=\mathrm{k}_{\mathrm{r}}\left(\mathrm{T}_{\max }-\mathrm{T}_{\min }\right)^{0.5}
$$

245 where $\mathrm{H}$ is the estimating global solar radiation $\left(\mathrm{W} / \mathrm{m}^{2}\right), \mathrm{H}_{0}$ is the daily mean value of extraterrestrial solar radiation $\left(\mathrm{W} / \mathrm{m}^{2}\right), \mathrm{T}_{\max }$ and $\mathrm{T}_{\min }$ are the daily mean values of maximum and minimum temperatures $\left({ }^{0} \mathrm{c}\right), \mathrm{k}_{\mathrm{r}}$ is the adjustment coefficient, $\mathrm{k}_{\mathrm{ra}}$ is the empirical coefficient for

248 arid and semi-arid regions it is initially taken as 0.17 and $\mathrm{P}$ is mean atmospheric pressure at the 249 site $(\mathrm{k} \mathrm{pa})$ and $\mathrm{P}_{0}$ is the mean atmospheric pressure at sea level (101.3k pa) and (h) is the altitude 250 of the site in meters (Chandel et al. 2005).

$251 \quad$ (2) Garcia model

252 Garcia model (1994) is one of the single parameters for estimating global solar radiation. This 253 model is an adaptation of the Angstrom- Prescott model, the clearness index is correlated with 254 the difference between the maximum and minimum temperatures $(\Delta T)$ is expressed in the form of (Abdulsalam et al. 2014)

$$
\frac{\mathrm{H}}{\mathrm{H}_{0}}=\mathrm{a}+\mathrm{b}\left(\frac{\Delta \mathrm{T}}{\mathrm{S}_{0}}\right)
$$

257 Here a and $\mathrm{b}$ are regression constants and $\mathrm{S}_{0}$ is the maximum day length (hours).

258 (3) Olomiyesan and Oyedum model

259 In 2016, a multilinear regression model was developed for the estimation of global solar 260 radiation. Olomiyesan and Oyedum model is on the new model with three regression constants 
261 (Olomiyesan et al. 2016). In this model, Garcia model was incorporated into Angstrom-Prescott 262 model is in the form of

263

$$
\frac{\mathrm{H}}{\mathrm{H}_{0}}=\mathrm{a}+\mathrm{b}\left(\frac{\mathrm{S}}{\mathrm{S}_{0}}\right)+\mathrm{c}\left(\frac{\Delta \mathrm{T}}{\mathrm{S}_{0}}\right)
$$

264 Where $\mathrm{a}, \mathrm{b}$ and $\mathrm{c}$ are the regression constants determined for study area.

\section{Relative humidity based models}

266 (1)Group 1

267 The clearness index is related with the relative humidity (RH) in the Group 1 model is the form 268 of

269

$$
\frac{\mathrm{H}}{\mathrm{H}_{0}}=\mathrm{a}+\mathrm{b}(R H)
$$

270 (2)Group 2

271

$$
\frac{\mathrm{H}}{\mathrm{H}_{0}}=\mathrm{a}+\mathrm{b}(R H)^{2}
$$

272 (3)Swartman- Ogunlade model

273 Swartman- Ogunlade in 1967 expressed global solar radiation in terms of relative sunshine and 274 relative humidity $(\mathrm{RH})$ as

$275 \quad \frac{\mathrm{H}}{\mathrm{H}_{0}}=\mathrm{a}+\mathrm{b}\left(\frac{\mathrm{S}}{\mathrm{S}_{0}}\right)+\mathrm{c}(R H)$

276 Where $\mathrm{RH}$ is the monthly average daily relative humidity (\%) and $\mathrm{S} / \mathrm{S}_{0}$ is the relative sunshine.

277

278

279

280

281

282

283

\section{Results and discussion}

\subsection{Monthly variation of solar radiation}

Figure 2 (a), (b) ,(c) and (d) shows the monthly mean daily variation and standard deviations of the sunshine hour, diffuse solar radiation $\left(\mathrm{H}_{\mathrm{d}}\right)$ global solar radiation $\left(\mathrm{H}_{\mathrm{cal}}\right)$ and extraterrestrial solar radiation $\left(\mathrm{H}_{0}\right)$ during April 2016 - October 2018 over the study area. The 
monthly mean daily variation of the sunshine hour was maximum in the summer months $(12.19 \pm 0.59)$ and minimum in the winter months $(11.81 \pm 0.11)$ respectively over the study period.

The sunshine hour for a given period is defined as the sum of the sub-period for which the direct solar irradiance exceeds $120 \mathrm{~W} / \mathrm{m}^{2} \mathrm{WMO}$ (2003). The sunshine was uttered as the regular number of hours of sunshine per month or year, and tabulating the real hours of sunshine, as a percentage possible duration of sunshine for the particular location indicates the relative sun shines of climate (Russell 1934). The sunshine hour is directly affects the result of global solar radiation. It is observed that the global and diffuse solar radiation were fairly high in summer $\left(344.77 \pm 33.24\right.$ and $\left.84.51 \pm 5.87 \mathrm{~W} / \mathrm{m}^{2}\right)$ months (March-May) and low in the winter and monsoon $\left(326.51 \pm 6.70\right.$ and $\left.76.89 \pm 8.22 \mathrm{~W} / \mathrm{m}^{2}\right)$ months (December - February) with total average values of $335.46 \pm 26.81$ and $80.36 \pm 8.68 \mathrm{~W} / \mathrm{m}^{2}$ respectively. The larger values of global and diffuse solar radiation during the summer months could be attributed to the maximum daily sunshine hours due to a high clearness index. In the presence of cloud and rainfall, suspension of water particles attenuates the incoming solar radiation to the earth's surface (Sansui, et al., 2015; Omondi Onyango et al. 2015) and hence the reduction in the amount of global solar radiation. Extraterrestrial solar radiation was high in May $\left(445.92 \pm 0.016 \mathrm{~W} / \mathrm{m}^{2}\right)$ and low in December $\left(333.98 \pm 0.053 \mathrm{~W} / \mathrm{m}^{2}\right)$. The sunshine duration $(\mathrm{S})$, global solar radiation $\left(\mathrm{H}_{\text {cal }}\right)$, extraterrestrial solar radiation $\left(\mathrm{H}_{0}\right)$, and diffuse solar radiation $\left(\mathrm{H}_{\mathrm{d}}\right)$ for Kadapa are presented in Table 1.

\subsection{Monthly variation of relative sunshine and global solar radiation with clearness index}

Figure 3 (a) shows the monthly variation of relative sunshine and clearness index during the period of three years (2016-2018) for the semi- arid region Kadapa. A similarity pattern was observed in both parameters with their significance values. Both values of relative sunshine and clearness index were maximum in November $2016(1.07 \pm 0.002$ and $1.00 \pm 0.005)$ due to the clear sky and hence the high global solar irradiance is experienced. In sky conditions classification, the clearness index is often used because it depends mainly on global solar irradiance. In another improvement, Fig. 3 (b) shows the monthly mean $\mathrm{K}_{\mathrm{t}}$, including the mean global solar radiation measured for the same periods from 2016-2018. It shows that the curves of mean $\mathrm{K}_{\mathrm{t}}$ values and the mean global solar radiation were in same pattern. Minimum values were observed in the monsoon month of July $2018(0.89 \pm 0.05$ and $0.65 \pm 0.072)$ due to the cloudy sky and the fairly low solar irradiance. The minimum value of $\mathrm{k}_{\mathrm{t}}$ indicates that huge fraction of global solar radiation is diffuse in the monsoon season. The seasonal values of both relative sunshine 
315 (clearness index) was observed in winter, summer, monsoon and post-monsoon are 1.044 \pm 0.021

316 (0.926 \pm 0.054$), \quad 0.984 \pm 0.043$ (0.787 \pm 0.072$), \quad 0.956 \pm 0.043 \quad(0.745 \pm 0.062)$, and $1.004 \pm 0.057$

$317(0.858 \pm 0.116)$ respectively over the study period. From the above observations in the Kadapa

318 region, the clear sky will fell within the winter and summer seasons and partly cloudy sky in 319 monsoon and post-monsoon seasons.

\section{3.3. Monthly variation of clearness index and diffuse fraction}

Figure. 4 shows the monthly variations of the clearness index $\left(\mathrm{k}_{\mathrm{t}}\right)$ and a diffuse fraction $322\left(k_{d}\right)$ for the Kadapa region from April 2016 to October 2018. The clearness index and diffuse fraction showed the sky conditions in the method of transmitting and scattering incoming solar radiation. The location of the sun relative to the study site and the level of humidity cause the variation in clearness index . The highest clearness index was observed in November 2016 (1.001 \pm 0.048$)$ and lowest in the monsoon month of July $2018(0.650 \pm 0.035)$. High global radiation conquered by the direct component of the radiation gives the higher values of clearness index, and low global solar radiation due to a cloudy sky with a high portion of diffuse components gives the lower clearness index. For the entire study period, the total average values of clearness index and diffuse index were $(0.823 \pm 0.100)$ and $(0.240 \pm 0.019)$ respectively. Table 2 shows the values of the monthly averaged daily sunshine hour $(\mathrm{S})$, relative sunshine $\left(\mathrm{S} / \mathrm{S}_{0}\right)$, clearness index $(\mathrm{kt})$ and diffuse fraction $\left(\mathrm{k}_{\mathrm{d}}\right)$ respectively.

\subsection{Seasonal wise Frequency and Commutative Frequency Distribution of Daily clearness} index and diffuse fraction Values

Figure 5(a), (b) shows the seasonal wise daily percentage frequency and cumulative frequency distributions of clearness index $\left(\mathrm{k}_{\mathrm{t}}\right)$ with 0.2 range and the diffuse fraction $\left(\mathrm{k}_{\mathrm{d}}\right)$ with 337 the range of 0.05 from 2016 - 2018. From Fig. 5(a), in all seasons the percentage frequency of $k_{t}$ was greater than 0.8 , indicates the clear sky condition in the Kadapa region. It is clear from the 339 figure, $\mathrm{k}_{\mathrm{t}}$ ranged from 0.8 to 1.0 with a frequency of $76.67 \%$ in winter season followed by 340 summer and post monsoon are $50.63 \%$ and $57.51 \%$ respectively. While it varied from 0.6 to 0.8 341 with that of $84.96 \%$ in monsoon season. In the case of diffuse fraction, a broad frequency 342 distribution was observed to be 0.15 to 0.35 from 2016 - 2018. From the Fig. 5 (b), $\mathrm{k}_{\mathrm{d}}$ indicates 343 the dispersing direct normal irradiance. The dispersed irradiance however finds its course to the 344 surface of the earth, which then brings about diffusion. 


\subsection{The correlation equation of the Models}

In the sunshine, temperature and relative humidity based models, there are different models were used to estimate the global solar radiation to show the validation of relative sunshine duration, $\Delta \mathrm{T}, \Delta \mathrm{T} / \mathrm{S}_{0}$ and clearness index for Kadapa during the period of April 2016 to October 2018. The regression constants and the coefficient of determination $\mathrm{R}^{2}$ values for sunshine, temperature and relative humidity based models were shown in table $3,4 \& 5$. The results of the models were summarized below; From the above summary, the regression equations formed due to the sunshine-based models were well correlated with the calculated values.

357 In summary, model 3 performed excellently in term of coefficient of determination $\left(\mathrm{R}^{2}\right)$ than model 1 and 2 while model 3 performed better than model 1 and model 2 has a 95.30\% coefficient of determination.

360 Model 3 performed excellently in terms of coefficient of determination $\left(R^{2}=0.953\right)$ compared to model 1, 2. From the above report, the calculated and the estimated values for study location is remarkable.

\subsection{Monthly variation of calculated and estimated clearness index using sunshine based} models

Figure 6 shows the estimation of the monthly mean daily global solar radiation using sunshine-based models for Kadapa during the period 2016-2018. From the figure there was good agreement between the calculated and model estimated values with a coefficient of determination of 0.951, 0.971, 0.959 and 0.964 for AP Model, Ogelman Model, El-metwally Model and Bakirci Model respectively.

372 remaining months are over estimated. From the model estimation, AP model, Ogelman Model,

373 El-metwally Model are over estimated and the Bakirci Model was under estimated to the 374 calculated values. The calculated and estimated clearness index using sunshine models were 375 shown in Table 6. 
3.7. Monthly variation of calculated and estimated clearness index using temperaturebased models

The comparison and correlation between the calculated and estimated global solar radiation using temperature-based models over the study location were shown in Fig. 7. In the temperature models, the maximum and minimum air temperature values and relative sunshine values are using during the study period. From the above figure the HS model was under estimated to the calculated values for all months with a coefficient of determination of $R^{2}=0.226$. The Garcia and Olomyesan models were over-estimated in January to July and under-estimated in August to December with a coefficient of determination of $R^{2}=0.334$ and 0.953 respectively. The Table 7 gives the summary of the calculated and estimated clearness index using the temperature-based models. The result shows that the accuracy of hybrid-parameters-based models is better than compared to single-parameter-based models.

3.8.Monthly variation of calculated and estimated clearness index using relative humidity

\section{based models}

Figure 8 shows the estimation of global solar radiation using the relative humidity (RH) and comparison with the calculated radiation. The figure shows that the months from May to September for the group I and group II models are over-estimated and the remaining months are under-estimated to the calculated values with a coefficient of determination of 0.465 and 0.426 respectively. The Swartman-Ogunlade model shows the best correlation $\left(\mathrm{R}^{2}=0.953\right)$ to the calculated radiation value. The results for the relative sunshine models were summarized below 399 in Table 8.

\section{4. Conclusions}

401 The estimation of monthly global solar radiation has been calculated by several empirical models 402 from the kinds of literature based on the sunshine, temperature and relative humidity model using 403 sunshine hour, relative sunshine, maximum and minimum temperatures and relative humidity 404 values. These meteorological parameters were collected from MOSDAC for Kadapa station from 405 January 2016 to December 2018. The atmospheric temperature (relative humidity) was high 406 (low) in the summer (winter) and low (high) in the winter (summer) months. The global solar 
radiation and diffuse solar radiation were high in summer months and low in monsoon months.

The estimated clearness index using different models; sunshine, temperature and relative humidity are good correlated with the calculated clearness index values.

CRediT authorship contribution statement.

\section{Funding}

This study was carried out under the financial support of Council of Scientific and industrial Research (CSIR- EMR I).

\section{Data availability:}

The datasets generated during and/or analysed during the current study are available from the corresponding author on reasonable request.

\section{Compliance with ethical standards}

Ethics approval and consent to participate Not applicable.

Consent for publication Not applicable.

Competing interests The authors declare that they have no competing interests.

424 The authors wish to thank Council of Scientific and Industrial Research for their financial 425 support under the project (CSIR-EMR I). The authors are indebted to the Indian Space Research Organization (ISRO) Bangalore, for their financially equipment support under ISRO-GBP (ARFI) project. The authors gratefully acknowledge MOSDAC (Meteorological and Oceanographic Satellite Data Archive Center) providing the meteorological data.

\section{References}

Abdusalam D, Mbamali I, Usman M, Bala K (2014) Insolation Levels Using Temperature Model for Sustainable Application of Photovoltaic Technology in Some Selected Locations of Nigeria. Journal of Energy Technologies and Policy.e-ISSN 2225-0573. 4(1): 19-28.

Adam ME (2012). Uses of Sunshine Duration to Estimate UVB Solar Radiation under Sky Cover Conditions at Qena (Egypt). Canadian Journal on Computing in Mathematics, Natural Sciences, Engineering and Medicine 3(1):19-33.

Agbo GA, Baba A, Obickezeie T N (2010) "Empirical model for the correlation of the monthly average global solar radiation with sunshine hours at Mina Niger State, Nigeria". Journal of Basic Physical Research 1(1): 41 - 47.

Ahmed A, Akhlaque M, Ahmad F, Akhtar MW (2009) Estimation of global and diffuse solar radiation for Hyderabad, Sindh, Pakistan. Journal of Basic and Applied Sciences 5(2):73-77. 


\section{DOI: $\underline{\text { 10.1115/1.1877512. }}$.}

483 Sons, Inc., New York.

Akhlaque AM, Firoz A, Wasim MA (2009) 'Estimation of Global and Diffuse Solar Radiation for Hyderabad, Sindh, Pakistan'. Journal of Basic and Applied Science 5 (2):73-77.

Akinoglu BG, Ecevit A (1990) "Construction of a quadratic model using modified Angstrom coefficients to estimate global solar radiation." Solar Energy 45: 85-92.

\section{DOI: 10.1016/0038-092X(90)90032-8.}

Allen RG (1997) A self calibrating method for estimating solar radiation from air temperature. Journal on Hydrologic Engineering ASCE 2:56-57.

Allen RG, Pereira LS, Raes D, Smith M (1998) Crop evapotranspiration: Guidelines for Computing crop requirements. Irrigation and Drainage 56: FAO, Rome, Italy.

Alnaser WE (1993) "New model to estimate the solar global irradiation using astronomical and meteorological parameters". Renewable Energy 3: 175-177.

Angstrom A (1924) Solar and Terrestrial Radiation. Journal of Meteorological Society 50:121126. https://doi.org/10.1002/qj.49705021008.

Bakirci K (2009) Correlations for estimation of daily Global Solar Radiation with hours of bright sunshine in Turkey." Energy, Elsevier 34(4): 485-501.

\section{DOI: 10.1016/j.energy.2009.02.005.}

Bannani FK, Sharif TA, Ben-Khalifa A (2006) "Estimation of monthly average solar radiation in Libya". Theoretical and Applied Climatology 83: 211-215.

Besharat F, Dehghan AA, Faghih AR (2013) Empirical models for estimating global solar radiation: a review and case study. Renewable \& Sustainable Energy Reviews 21:798-821. http://dx.doi.org/10.1016/j.rser.2012.12.043.

Bristow KL, Campbell GS (1984) On the relationship between incoming solar radiation and daily maximum and minimum temperature. Agricultural and Forest Meteorology 31: 159-166.

Chandel SS, Aggarwal RK, Pandey AN (2005) "New correlation to estimate global solar radiation on horizontal surfaces using sunshine hour and temperature data for 16 Indian sites". Journal of Solar Energy Engineering 127(3): 417-420.

Duffie JA, Beckman WA (1991) Solar Engineering of Thermal Processes, 3rd ed. (John Wiley \&

El-Metwally M (2004) Simple new methods to estimate global solar radiation based on meteorological data in Egypt. Atmospheric Research 69: 217.

http://dx.doi.org/10.1016\%2Fj.atmosres.2003.09.002. 
Ertekin, Can \& Yaldız, Osman (1999) "Estimation of monthly average daily global radiation on

Falayi EO, Rabiu AB (2005) "Estimation of global solar radiation using cloud cover and surface temperature in some selected cities in Nigeria." Archives of Physics Research 2(3): 99109.

Fedorov VM (2019) Earth insolation variation and its incorporation into physical and mathematical climate models. Uspekhi Fiz. Nauk 189: 33-46.

Fletcher AL, Moot DJ (2007) "Estimating daily solar radiation in New Zealand using air temperatures". New Zealand Journal of Crop and Horticultural Science 35:147-157.

Gana NN, Akpootu DO (2013b) Estimation of global solar radiation using four sunshine based models in Kebbi, North-Western, Nigeria. Advances in Applied Science Research 4:409421.

Garcia JV (1994) Physical principles of climatology. Ediciones UNALM (Universidad NacionalAgraria La Molina: Lima, Peru).

Ghazi S, Ip, K (2014) The effect of weather conditions on the efficiency of PV panels in the southeast of UK. Renewable Energy 69: 50-59. DOI: 10.1016/j.renene.2014.03.018.

Hargreaves G, Samani Z (1982) Estimating potential evapotranspiration. Journal of Irrigation and Drainage Engineering. ASCE 108: 225-230.

Hussain M, Rahman L, Mohibur Rahman, M (1999) Techniques to obtain improved predictions of global radiation from sunshine duration. Renewable Energy 18: 263-275.

https://doi.org/10.1016/S0960-1481(98)00772-1.

Jatto MA, Shuaibu AY, Garba I (2015) Investigation ofthe global solar energy potential in Potiskum, Yobe state Nigeria. Proceedings of theInternational AcademicConference for SubSahara African Transformation \&Development.

Kaltiya MS, Abubakar MS, Itodo IN (2014) "Prediction of Global Solar Radiation Using Angstrom-Page Equation Model for Benue State, Nigeria". American Journal of Energy Research (AJER) e-ISSN : 2320-0847. 03(23): 145-150.

Khin C, Buasri P, Chatthawom R, Siritaratiwat A (2018) Estimation of Solar Radiation and Optimal Tilt Angles of Solar Photovoltaic for Khon Kaen University. International Electrical Engineering Congress.

Koussa M, Malek A, Haddadi M (2009) "Statistical comparison of monthly mean hourly and daily diffuse and global solar irradiation models and a Simulink program development for various Algerian climates.” Energy Conversion and Management, 50: 1227-1235.

http://dx.doi.org/10.1016/j.enconman.2009.01.035. 
Kumar R, Umanand L (2005) "Estimation of global radiation using clearness index model for sizing photovoltaic system". Renewable Energy 30, 2221-2233.

\section{DOI: 10.1016/j.renene.2005.02.009.}

Li MF, Liu H B, Guo PT, Wu W (2010) "Estimation of daily solar radiation from routinely observed meteorological data in Chongqing, China". Energy Conversion and Management 51: 2575-2579. http://doi.org/10.1016/j.enconman.2010.05.021.

Li H, Bu X, Lian Y, Zhao L, Ma W (2012) Further investigation of empirically derived models with multiple predictors in estimating monthly average daily diffuse solar radiation over China. Renewable Energy 44: 469-473. DOI: 10.1016/j.renene.2012.01.104.

Manual Collares-Pereira, Ari Rabl (1979) The average distribution of solar radiationcorrelations between diffuse and hemispherical and between daily and hourly insolation values. Solar energy 22: 155-164. http://dx.doi.org/10.1016/0038-092X(79)90100-2.

Mecibah M, Boukelia T, Tahtah R, Gairaa K (2014) "Introducing the best model for estimation the monthly mean daily global solar radiation on a horizontal surface (Case study: Algeria)". Renewable \& Sustainable Energy Reviews 36:194-202. DOI: 10.1016/j.rser.2014.04.054.

Medugu DW, Yakubu D (2011) Estimation of Mean Monthly Global Solar Radiation in Yola (Nigeria) using Angstrom Model. Advances in Applied Science Research ISSN: 09768610. 2 (2): 414-421.

Muhammad A, Darma TH (2014) "Estimation of Global Solar Radiation for Kano State, Nigeria. Based on Meteorological data.” IOSR Journal of Applied Physics 6(6): 19-23.

Muneer T, Munawwar (2006) Improved Accuracy Models for Hourly Diffuse Solar Radiation. Journal of Solar Energy Engineering 128 (1): 104-117. http://dx.doi.org/10.1115/1.2148972.

Nwokolo SC, Ogbulezie JCA (2017) Quantitative review and classification of empirical models for predicting global solar radiation in West Africa. Beni-Suef University. Journal of Basic Applied Sciences 78: 955-995. http://dx.doi.org/10.1016/j.bjbas.2017.05.001.

Ogelman H, Ecevit A, Tasdemiroglu E (1984) “A New Method for Estimating Solar Radiation from Bright Sunshine Data”. Solar Energy 33(6): 619-625. doi:10.1016/0038-092X(84)90018-5.

Olomiyesan BM, Oyedum OD (2016) Comparative Study of Ground Measured, SatelliteDerived and Estimated Global Solar Radiation Data in Nigeria. Journal of Solar Energy 81973897. https://doi.org/10.1155/2016/8197389.

Omondi Onyango A, Victor Ongoma (2015) Estimation of mean monthly global solar radiation using sunshine hours for Nairobi City, Kenya. Renewable \& Sustainable Energy Reviews 7: 053105. https://doi.org/10.1063/1.4930530. 
Page J K (1964) The estimation of monthly mean values of daily total short - wave radiation on 585 vertical and inclined surfaces from sunshine records. Proceeding of the UN Conference on New 586 Sources of Energy 98.

Paulescu M, Fara L, Tulcan-Paulescu E (2006) Models for obtaining daily global solar irradiation from air temperature data. Atmospheric Research 79: 227-240.

\section{http://dx.doi.org/10.1016\%2Fj.atmosres.2005.06.001.}

Prescott JA (1940) Evaporation from water surface in relation to solar radiation. Transactions of the Royal Society of Australia 46:114-118. https://doi.org/10.4236/jss.2014.28019.

Rietveld MR (1978) "A new method for estimating the regression coefficients in the formula relating solar radiation to sunshine". Agricultural and Forest Meteorology 19: 243-252. https://doi.org/10.1016/0002-1571(78)90014-6.

\section{Ruiz-Arias JA, Alsamamra H, Tovar-Pescador J, Pozo-Vázquez D (2010) Proposal of a}

regressive model for the hourly diffuse solar radiation under all sky conditions. Energy Conversion and Management 51: 881-893.

Russell RJ (1934) Climate Years. Geographical Review 24: 92-103.

\section{https://doi.org/10.2307/209496.}

Sanusi YK, Ojo MO (2015) Evaluation of Clearness Index and Diffuse Ratio of Some Locations in South Western, Nigeriausing Solar Radiation Data. IOSR Journal of Applied Physics (IOSRJAP) e-ISSN: 2278-4861. 7(5):45-51.

Srivastava RC, Harsha Pandey (2013) Estimating Angstrom-Prescott Coefficients for India and Developing a Correlation between Sunshine Hours and Global Solar Radiation for India. ISRN Renewable Energy Article ID 403742, 7 pages. https://doi.org/10.1155/2013/403742.

Teke A, Y1ldırım H (2014) "Estimating the monthly global solar radiation for Eastern Mediterranean Region”. Energy Conversion and Management 87: 628-635.

\section{DOI: 10.1016/j.enconman.2014.07.052.}

Trabea AA, Mosalam Shaltout MA (2000) Correlation of global solar radiation with meteorological parameters over Egypt. Renewable Energy 21 (2): 297-308.

DOI: 10.1016/S0960-1481(99)00127-5.

Vasudeva Reddy M, Padma Suvarana R, Pavan Kumari S, Balakrishnaiah G, Rama Gopal K, (2018) Estimation of global solar radiation using sunshine and temperature based models over Anantapur region. International Journal of Creative Research Thoughts (IJCRT) 6(2) ISSN: 2320-2882.

World Meteorological Organization (WMO), (2003) Manual on the Global Observing. 
630 World Meteorological Organization (WMO), (2006) Guide to Meteorological Instruments and 631 Methods of Observation 8:158-167.

Yusuf A (2017) Characterization of sky conditions using clearness index and relative sunshine duration for iseyin, Nigeria, International journal of Physical Sciences Research 1: 53-60. DOI: $10.9790 / 4861-07524551$.

Zeng J, Qiao W (2011) Short-Term Solar Power Prediction using an RBF Neural Network. IEEE Power and Energy Society General Meeting. DOI: 10.1109/PES.2011.6039204.
Affiliations
1. ${ }^{1}$ Atmospheric Science Laboratory, Department of Physics, Yogi Vemana University, Kadapa 516 005, Andhra Pradesh, India
2. ${ }^{2}$ Department of Physics, University of Petroleum and Energy Studies, Dehradun, Uttarakhand 248007,India
3. ${ }^{3}$ Aerosol \& Atmospheric Research Laboratory, Department of Physics, Sri Krishnadevaraya University, Anantapur 515 003, Andhra Pradesh, India 
Figures
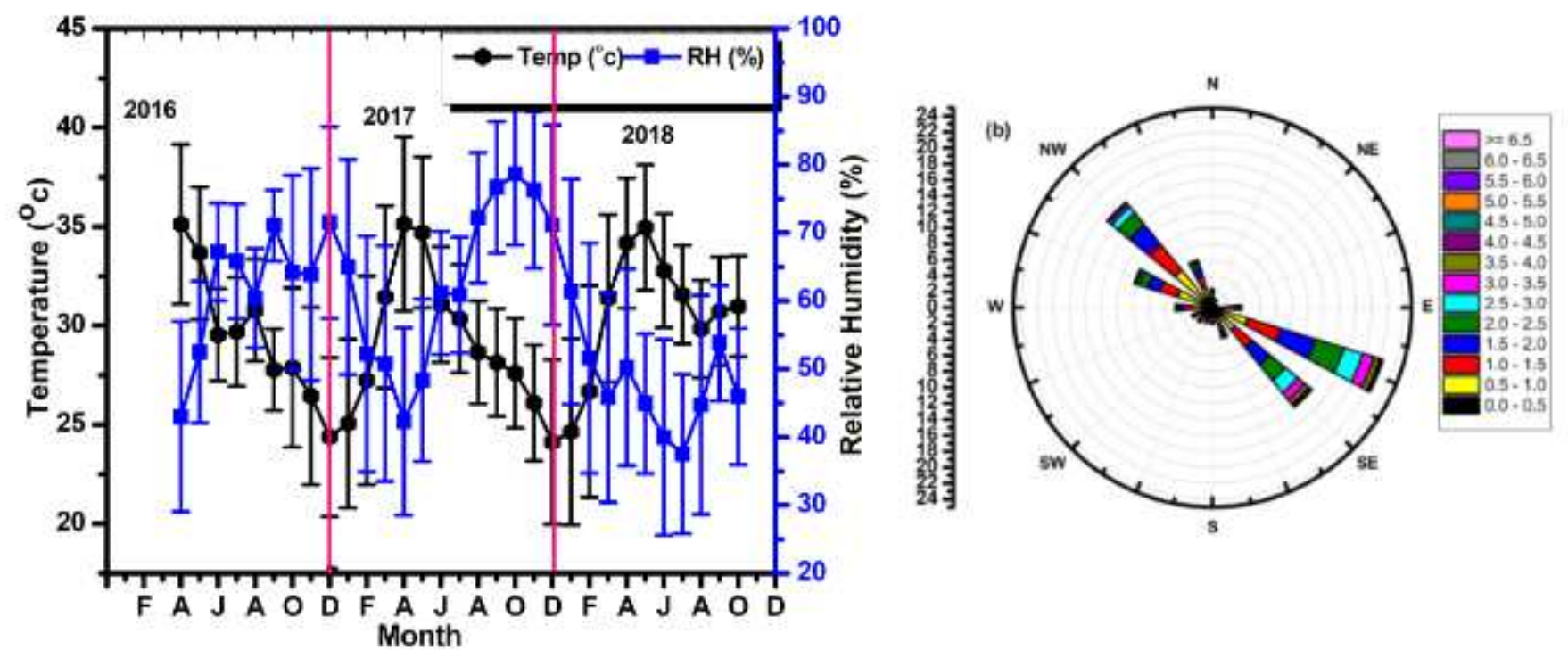

Fig. 1

Figure 1

(a) Monthly variation of atmospheric temperature and relative humidity $(\mathrm{RH})$, (b) wind rose over the study location during April 2016 to October 2018. 


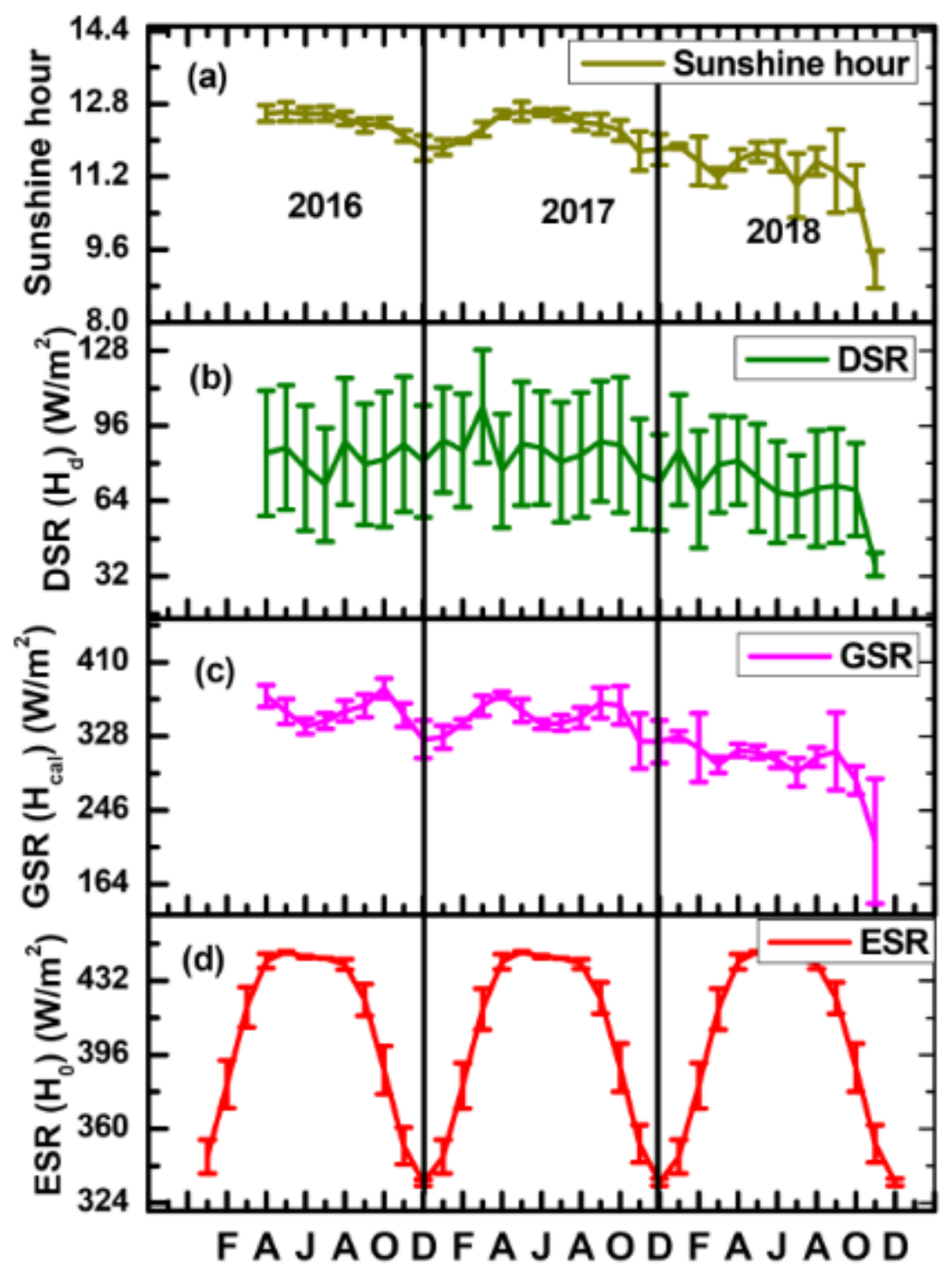

Fig. 2

Figure 2

Monthly means daily variation of sunshine hour, global, extraterrestrial and diffuse solar radiation in kadapa during the study period 2016-2018. 


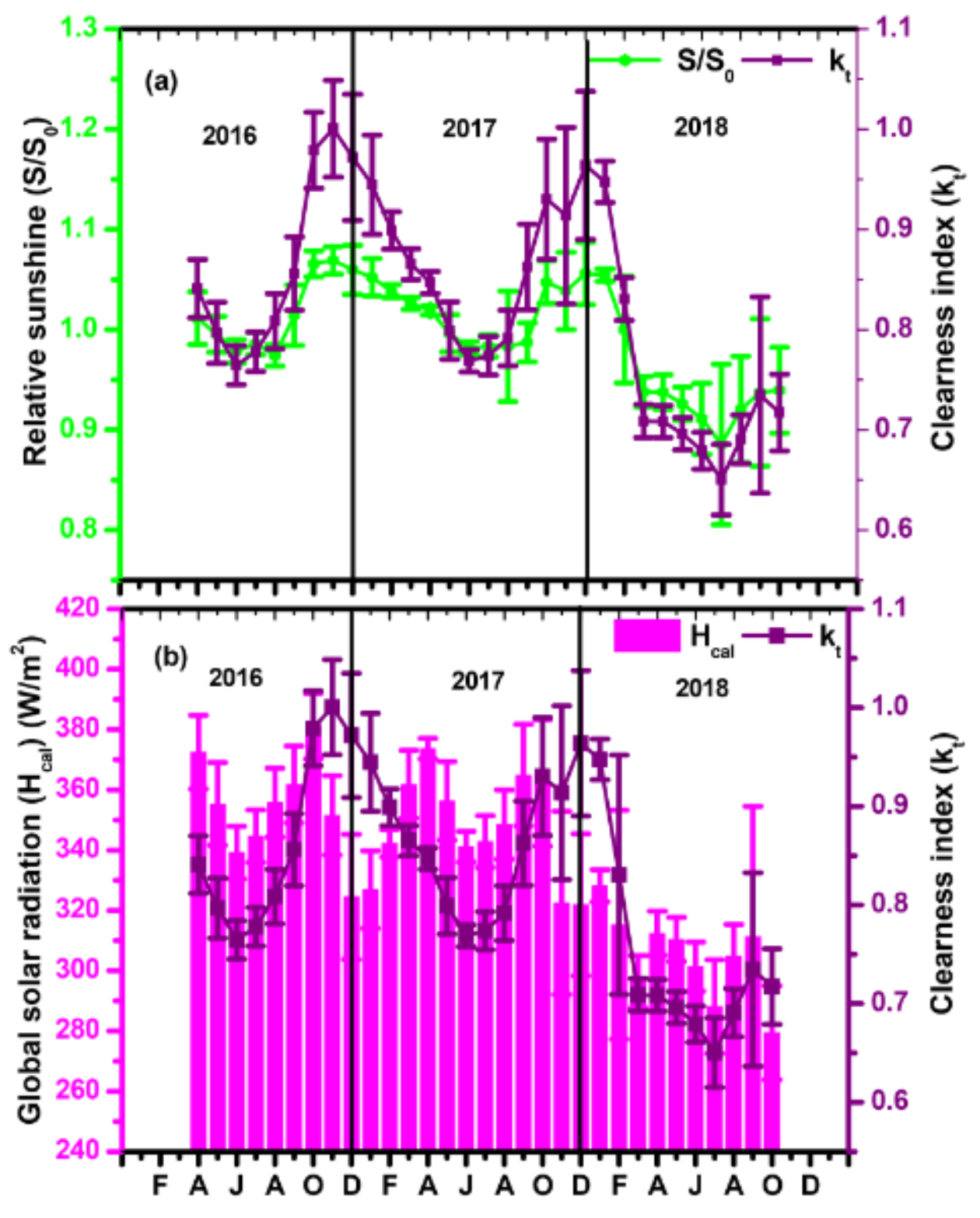

Fig. 3

Figure 3

Monthly variation of (a) relative sunshine and (b) global solar radiation with clearness index over the study location. 


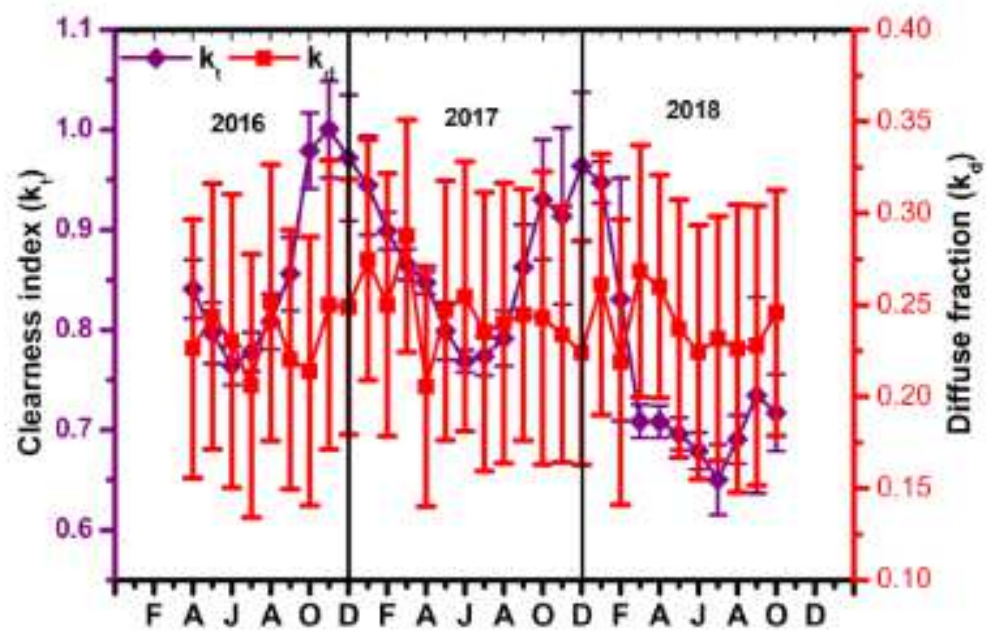

Fig. 4

Figure 4

Monthly variation of clearness index $\left(k_{t}\right)$ and diffuse fraction $\left(k_{d}\right)$ over the study. 
(a)
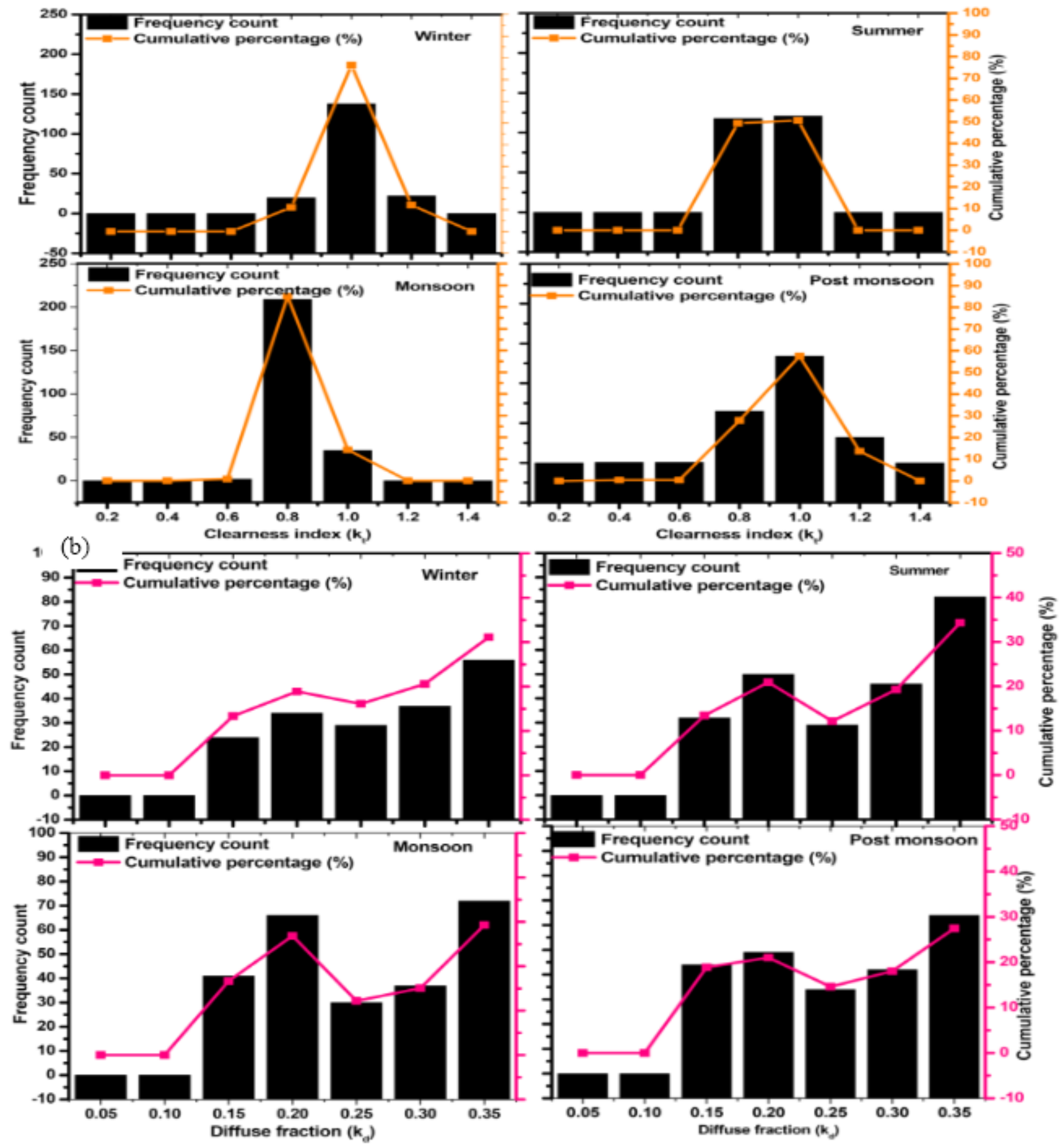

Fig. 5

\section{Figure 5}

The seasonal pattern of frequency and cumulative frequency of (a) clearness index $\left(k_{t}\right)$ and (b) diffuse fraction $\left(k_{d}\right)$ in Kadapa for the years 2016-2018. 


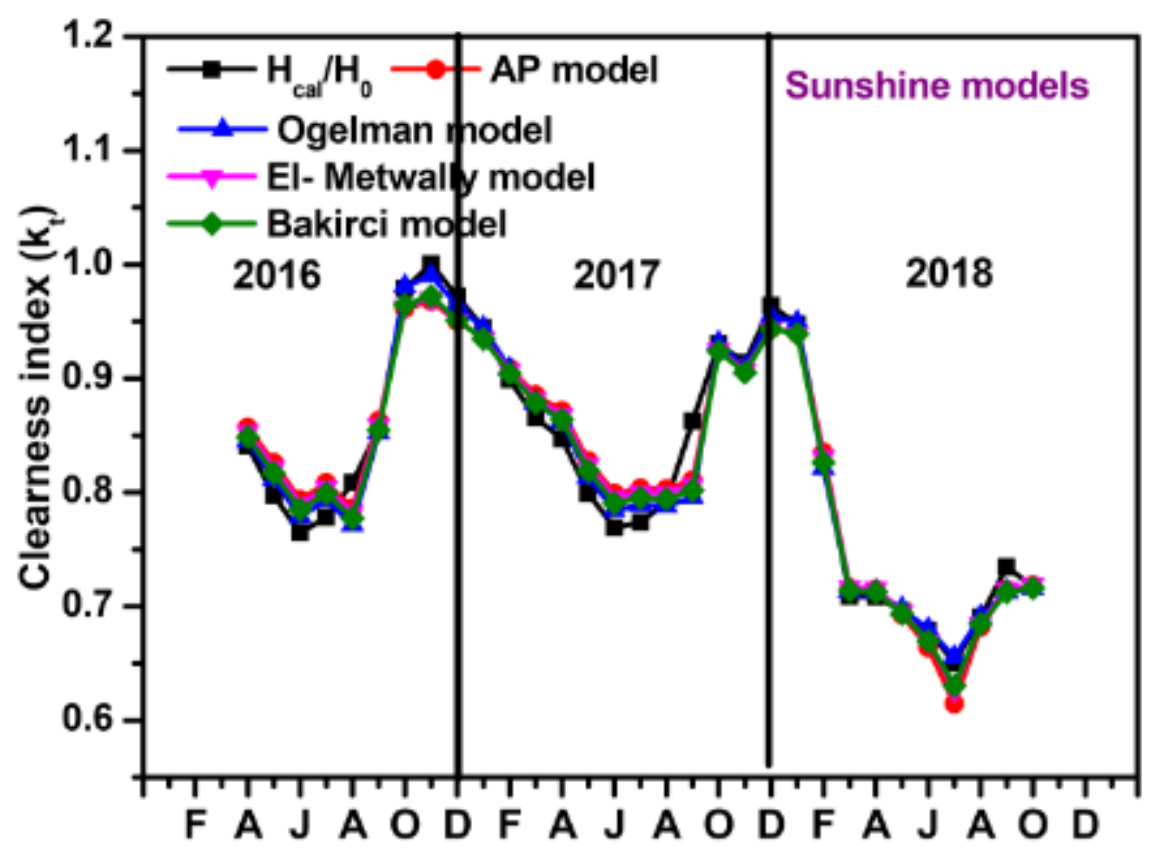

Fig. 6

Figure 6

Monthly variation of calculated and estimated global solar radiation using sunshine based models.

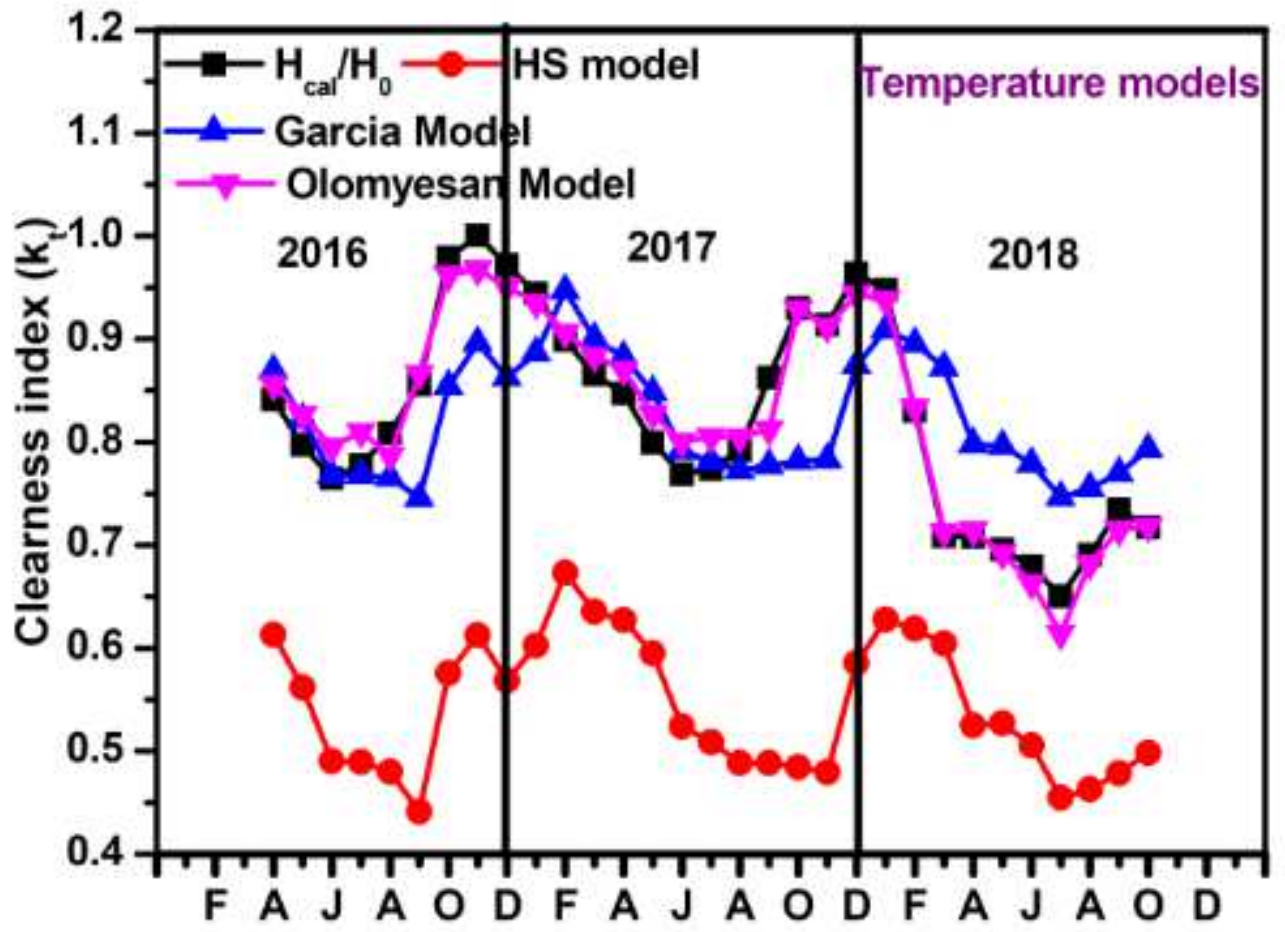

Fig. 7 
Figure 7

Monthly variation of calculated and estimated global solar radiation using temperature based models.

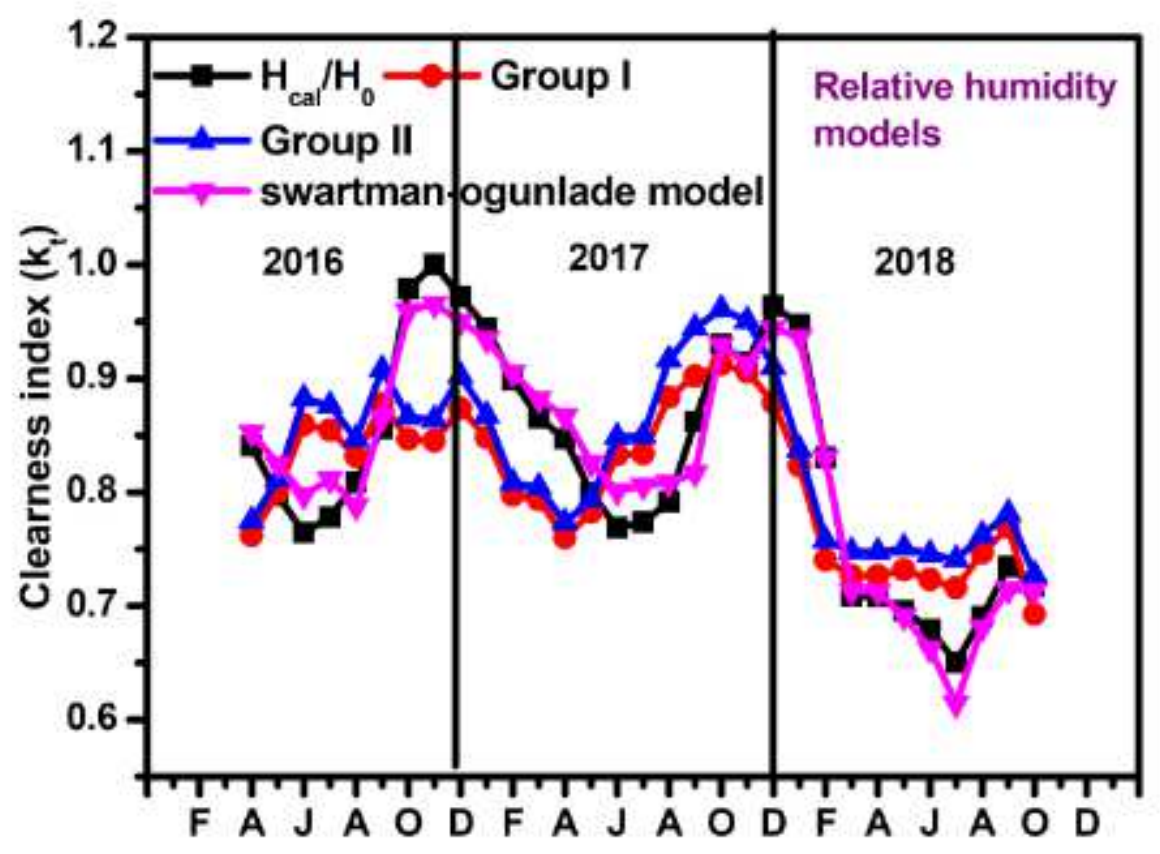

Fig. 8

Figure 8

Monthly variation of calculated and estimated global solar radiation using relative humidity based models.

\section{Supplementary Files}

This is a list of supplementary files associated with this preprint. Click to download.

- table.doc 